\title{
Emerging Themes in a Distance-Delivered Calculus I Course: Perceptions of Collaboration, Community and Support
}

\section{Ms. Angela Minichiello, Utah State University}

Angie Minichiello is a Principal Lecturer in the Department of Engineering Education at Utah State University. She instructs undergraduate engineering courses via distance delivery to students at regional campuses located throughout Utah. She is a registered professional mechanical engineer and has more than 15 years industry experience as a practicing engineer. Angie's research interests include understanding barriers to entry and persistence in engineering, diversity issues in engineering, and distance delivered engineering education. She is member of ASEE, ASME and IEEE.

\section{Dr. Joshua Marquit, Utah State University}

Joshua Marquit is an Instructor in the Psychology Department at Utah State University. He has a doctoral degree in psychology, with an emphasis on applied and experimental methodology. He teaches undergraduate and graduate research methods and statistics courses on campus, online, and through distance broadcast learning formats. He has previous research experience with the U.S. National Parks Service, NASA, and Utah Department of Environmental Quality. His research interests include computer-mediated communication, Internet infidelity, online medical information and its impact on the doctor-patient relationship, physical and verbal abuse among college athletes, gender role stereotypes, human interactions with various environments, and religiosity.

\section{Jim Dorward, Utah State University}

Jim Dorward is the Associate Dean for Research and Professor of Education at Utah State University. He specializes in Program Evaluation, Research Methods, and Mathematics Education. His collaborations in STEM project-based research include the National Library of Virtual Manipulatives, the National Center for Engineering and Technology Education, an evaluation capacity building service project for the Math and Science Partnership program, and the Instructional Architect (service software for the National STEM Digital Library).

\section{Dr. Christine E. Hailey, Utah State University}

Christine Hailey is Dean of the College of Engineering at Utah State University and a Professor of Mechanical and Aerospace Engineering. She has served as a senior associate dean in the college and was the director of the National Center for Engineering and Technology Education, a National Science Foundation-funded center for learning and teaching. She was a member of the ADVANCE-US team, another NSF-funded program to address issues that impact the effectiveness and satisfaction of female faculty in the engineering and science colleges at USU. 


\title{
Emerging Themes in a Distance-Delivered Calculus I Course: Perceptions of Collaboration, Community and Support
}

\begin{abstract}
Our national interest in educating greater numbers of engineers puts emphasis on creating undergraduate engineering education opportunities accessible by traditionally underrepresented student groups, including geographically dispersed and rural residents, working professionals, and women. Currently, new pathways to engineering are being realized via distance delivery and online learning. As more engineering programs adopt distance delivery as a means to engage a larger and more diverse student pool, significant needs for transformational pedagogy capable of supporting contemporary learning environments arise. For distance engineering students, educational intervention within the required calculus sequence may be most critical as data indicates that student success rates in distance delivered calculus sections are as low as $48 \%$.

This paper describes the first year activities of an NSF sponsored TUES Type I project entitled "Online Learning Forums for Improved Engineering Student Outcomes in Calculus." In this three-year study, we are evaluating the potential of web-based learning communities, as implemented through a freely available, wiki-based online platform, to improve student outcomes in distance delivered calculus. Using a mixed methods approach, we are assessing changes in academic achievement, interest in mathematics and engineering, and attitudes toward learning among introductory calculus students located at several regional sites throughout the state. Data from multiple measures taken from students enrolled in the introductory calculus sequence using the wiki-based forum will be compared with findings from the current group of students. A major outcome of this project will be the development and dissemination of a usage model to facilitate broader use of online learning forums throughout Science, Technology, Engineering and Mathematics (STEM) education.

Recent data gathered from the control group of Calculus I students includes exam scores, an end of course student survey, targeted student interviews, classroom observations and instructor reflection. Preliminary findings described herein will be used to inform implementation of the online learning forum in the Calculus I and II treatment sections, as well as serve as a baseline condition for comparison with data gathered during the next phase of the project.
\end{abstract}

\section{Introduction}

Efforts to graduate more engineering students and to promote their entry into the U.S. workforce as engineers are considered vital to our country's ability to maintain a position of global leadership, economic prosperity and national security ${ }^{1}$. Within Science, Technology, Engineering and Mathematics (STEM) education, data suggests that the U.S. is no longer producing sufficient graduates, in terms of numbers, skills, or diversity, to maintain its globally preeminent role. The effects of this "national debt of [U.S.] engineering talent"2 are intensified as other countries currently experience explosive STEM growth within their own programs. Thus, engineering education retention efforts currently receive high visibility and substantial support at national, state and local levels. 


\section{Background}

In 2009, Utah State University began a major effort to increase its number of engineering graduates by implementing distance delivery of its pre-professional (first two years) engineering program. The goal of this program is to extend access to engineering to student groups present within the region but consistently underrepresented within its engineering programs. These groups include geographically dispersed and rural residents, women re-entering the workforce, and working professionals. Courses are delivered synchronously, using interactive video conferencing (IVC) or "synchronous broadcast", in the evening hours to students at regional campuses and education centers located throughout the state. The ultimate success of the program is predicated on its ability to reduce barriers to education commonly experienced by these groups: cost (relocation expense), risk (degree completion), schedule (full time or part time employment) and time (family responsibilities).

Data gathered during the first three years (2009-2011) indicate that significant barriers to retention continue to exist for students enrolled in the program. Student achievement data showed that the rate (52\%) at which students were unsuccessful (final course grade of W, D or F) in distance delivered sections of Calculus I was not only alarmingly high, but was also nearly double the rate $(28 \%)$ for students in traditionally taught (face-to-face) sections. Moreover, on university administered end-of-course student evaluations, distance sections scored approximately one full point lower (on a scale of 1-poor to 6-excellent) than traditionally taught sections in ratings of instructor effectiveness (4.10 distance 4.91 traditional) and overall course quality (3.96 distance 4.90 traditional). These data point to the need for research aimed at better understanding the nature of the barriers to retention experienced by students in the distancedelivered engineering program.

The freshman calculus sequence (Calculus I and II) is often pointed to as a gatekeeper or filter for engineering education since it is pre-requisite for even the most fundamental engineering courses. Moreover, strong mathematical and reasoning skills are vital to success as an engineer. A review of the literature concerning engineering retention finds several studies ${ }^{3-5}$ reporting strong correlation between academic performance in first year calculus and attainment of an engineering degree. These studies suggest that the degree of student performance (e.g. grade), apart from merely passing the courses, is important to ultimate success in engineering. A recent longitudinal study ${ }^{3}$ further indicates that success, measured solely by the grade achieved in the first semester of college mathematics, independent of secondary mathematics preparation or achievement, is by itself a reliable predictor of retention among engineering undergraduates. This research underscores the importance for engineering education of developing a more thorough and complete understanding of the effective use of interventions aimed at improving outcomes in calculus. Impactful interventions with potential for use across the spectrum of delivery platforms (traditional, hybrid, synchronous broadcast, asynchronous online) could be transformative.

\section{The Project}

The work described herein is part of a three-year study funded by the National Science Foundation (NSF) ${ }^{6}$. The overall purpose of the study is to better understand use of online 
learning forums as interventions within STEM education. Its specific goals are to 1) implement and 2) assess student academic achievement and affective outcomes (engagement and attitudes towards learning) of an online learning forum implemented within the engineering calculus sequence and 3) develop a usage model to facilitate use of online learning forums as instructional interventions within STEM education.

To accomplish these goals, we are using a concurrent mixed methods ${ }^{7}$ approach in which data is gathered using a quasi-experimental, non-equivalent control group design within distance delivered (synchronous broadcast) sections of Calculus I and II. The experimental treatment is a freely available, wiki-based, online learning forum called Piazza (www.piazza.com).

Quantitative data, in the form student exam scores and responses to an end of course survey, and qualitative data, consisting of targeted student interviews, classroom observation, instructor reflections and artifacts (forum posts), are gathered and analyzed to evaluate online forum effectiveness and to develop the usage model.

\section{Theoretical Framework}

Social constructivism (Social Development Theory), as pioneered by Lev Vygotsky, asserts that learning is not simply ".... an unfolding or maturation of pre-existing 'ideas"; on the contrary, it is the formation of such ideas-out of what originally was not an idea- in the course of socially meaningful activity" ${ }^{\prime \prime}$. As a learning theory, social constructivism accounts for what many hold to be true: Learning is a socially and culturally participatory process ${ }^{8-10}$. People learn as a result of social interaction and cultural belonging; we build and rebuild our knowledge within context of our own familial and social groups, classrooms, and communities. Our desire to learn (social motivation) increases as we see ways to apply knowledge to help others, especially those whom we know and those within our local communities ${ }^{11}$. In essence, social constructivism "...[places] communication and social life at the center of meaning-making""

A more prominent theory of learning within the mathematics education community over many years has been Piagetian or cognitive constructivism. Cognitive constructivism emphasizes the "...autonomy of the individual in the construction of her or his knowing..."12. Despite cognitive constructivism's strong history of influence within mathematics education, we adopt social constructivism as a theoretical frame for our study because it emphasizes the contextual factors of the learning environment (situated learning) and the intersubjectivity ${ }^{12}$ of the learners over individual cognition. In this manner, social constructivism allows for the influence of an active and involved instructor (e.g. Vygotsky's Zone of Proximal Development) as well as for nuances of situated learning occurring within a classroom community- even if that community interacts at a distance via technology.

In adopting a socio-cultural perspective, one may envision how technology and computer based tools can be used to connect (rather than separate) learners and thus work to promote (rather than inhibit) learning: telecommunications provide means for interactivity and dialogue during and outside of classroom hours, access to the internet unlocks a plethora of informational resources for comparison and critical review, and networked learning tools can be implemented to facilitate and inspire collaboration. Thus, within a social constructivist framework, we hypothesize that the implementation of an online learning forum will work to improve student 
achievement and affective outcomes. Moreover, we would expect to gain a rich and deep understanding concerning how mathematics learning in a distance environment is affected by the implementation of the online forum from a socio-cultural stance.

\section{Research Questions}

Moving toward our project goals, we describe in this paper results of a preliminary analysis of data taken from the Calculus I control group during the fall 2013 semester. The current work seeks to illuminate themes related to student sense of collaboration, community and support. The data that will ultimately help us to answer the two research questions:

1. How does student academic achievement vary with respect to participation in the forum?

2. How does student interest in and attitudes toward learning calculus vary with respect to participation in the forum?

\section{The Context of the Synchronous Broadcast "Classroom"}

A broadband and digital broadcast network that serves both public and higher education throughout our state provides synchronous broadcast capability. This network connects more than 1000 public schools, 9 state colleges and universities, and 8 applied technology campuses while providing network services for more than 841,000 students, teachers, faculty and staff.

The synchronous broadcast learning environment melds a traditional "face-to-face" single classroom environment with interactive video conferencing technology to allow a single instructor to teach students physically located at multiple satellite locations simultaneously and in real time. A broadcast instructor, therefore, concurrently teaches students located in the same origination room as well as remote students via electronic video and audio feeds. Broadcast instructors can easily see and hear the students located in the same room; they see students at remote sites using flat screen monitors that display a tiled mosaic of the remote site classrooms ("Brady Bunch" style). While broadcast instructors can quite easily detect the site ID from which a remote student is speaking, the instructor may or may not be able to visually see or recognize the individual student depending upon the electronic configuration of the classroom. Anecdotally, recognition of students at remote sites is more often accomplished by the students identifying themselves and, over time, voice recognition rather than through visual cues.

Students located at the origination site experience the instruction in much the same way as they would in a face-to-face classroom. The instructor can display notes and other materials or work problems for the students to view using a projector with input from either a touch screen capable computer (which allows for note taking and annotations) or a document camera. Students located at origination sites usually do not have access to visual images of the remote students during the class, although this capability is slowly becoming available in more classrooms as they are upgraded with multiple displays. Anecdotally, the lack of visual cues to the remote students may contribute to the tendency of students in origination classes to forget that there are remote students as part of the class. Origination classrooms are equipped with desktop push button style microphones that students must enable prior to speaking or asking a 
question. In some classrooms, automatic overhead student microphones that do not require activation prior to speaking are available.

Students located at the remote sites experience instruction through video and audio feed. The video data is configured in a tiled arrangement with the instructor's projected workspace displayed prominently and a smaller view of the instructor superimposed (picture in picture). Remote site students can see the students from any site through the use of voice switching technology (camera view changes to the site that is speaking). In this configuration, students at the remote site will have visual access to students located at the origination site (or other remote sites) when the latter uses the microphone. Students at the remote sites are equipped with the same desktop microphones as those at the origination site.

For classes with large enrollment, there are classroom facilitators present during class to handle all technological issues in real time. For courses with small enrollments, facilitator assistance is available but not immediate as facilitators are dedicated to those classrooms. The number of students located at any site can vary from as few as one (which is common for remote sites) to multiple (20-30) students.

\section{The "Nontraditional" Undergraduate}

When it comes to undergraduate education, "nontraditional students" are becoming the new norm. In "Findings from the Condition of Education 2002: Nontraditional Undergraduates," the National Center for Education Statistics (NCES) concludes:

The traditional student, characterized here as one who earns a high school diploma, enrolls full time immediately after finishing high school, depends on parents for financial support, and either does not work during the school year or works part time- is the exception rather than the rule. In 1999-2000, just 27 percent of all undergraduates [from all types of post secondary institutions, including less-than-2 year, 2-year and 4-year] met all of these criteria. ${ }^{13}$

Acknowledging the lack of a precise definition of "nontraditional", Horn ${ }^{14}$ presents use of a continuum model for describing the degree to which students display nontraditional characteristics. A "nontraditional student" is someone who possesses any one of the following characteristics:

- delays enrollment (does not enter postsecondary education in the same calendar year that he or she finishes high school);

- attends part-time for at least part of the academic year;

- works full-time (35 hours or more per week) while enrolled;

- is considered financially independent for purposes of determining eligibility for financial aid;

- has dependents other than a spouse (usually children, but may also be caregivers of sick or elderly family members);

- is a single parent (either not married or married but separated and has dependents); or 
- does not have a high school diploma (completed high school with a GED or other high school completion certificate or did not finish high school).

Moving across the continuum, students may be considered "minimally nontraditional" if they possess only one characteristic, "moderately nontraditional" of they possess two or three characteristics, and "highly nontraditional" if they possess four or more characteristics. Thus, between $1999-2000$, it can be said that $73 \%$ of the undergraduates in this country were in some way nontraditional.

\section{Methodology}

Employing a concurrent mixed methods design, we are simultaneously gathering quantitative and qualitative data to answer the research questions. Our reason for choosing a mixed method approach for this research is based on the work of Bryman ${ }^{15}$ and is described as "completeness ... the notion that the researcher can bring together a more comprehensive account of the area of enquiry in which he or she is interested if both quantitative and qualitative research are employed." The quantitative and qualitative data are collected independently during the control and treatment sections of the distance delivered calculus course sequence. Final inferences will be based on the analysis of all data.

The control Calculus I section was taught on Tuesdays and Thursdays evenings from 8:00-10:30pm via synchronous broadcast during the fall 2013 semester. The semester consisted of 15 instruction weeks and one final exam week. The instructor (who teaching all courses involved in this study) is an experienced mathematics instructor with over 15 years teaching college calculus and 10 years teaching in a synchronous broadcast environment.

Student sample. The course had an initial enrollment of 26 students (5 female, 21 male) situated across seven regional locations ( 1 origination and 6 remote sites). Twelve of 26 students (46\%) were located at remote sites. Of the initial 26 enrollees, 2 remote ( 1 female and 1 male) students withdrew prior to the third week of course instruction. An additional 5 students (1 female, 4 male), 3 remote and 2 origination, withdrew after the third week but prior to $10^{\text {th }}$ week of instruction (last allowable day to withdraw). Nineteen of the 26 students (73\%) completed instruction and took the final exam. Of the 19 students completing the course, 12 were located at the origination site and 7 were distributed across 5 remote sites.

\section{Methods of Data Collection.}

Student grades. A quasi-experimental design component calls for the use of student exam scores as a quantitative measure of student achievement ${ }^{6}$. Because the final course grade is based purely on exam and quiz scores (no homework or participation grades are included in the final score grade) the final exam score is used in this work as a convenient measure of student achievement. The student final exam score in the course will serve as the post-test result. An average of student final exam scores for pre-requisite courses (algebra and trigonometry) will serve as the pretest score. Pretest and post-test scores will be used during statistical analysis to reduce significant threats to internal validity caused by selection bias (non-random assignment of students to control and treatment groups). 
Student survey. Affective course outcomes are measured using a 55 question online survey. The survey consists of 50 closed-ended (Likert scale) questions and 5 open-ended questions relating to sample demographics (e.g., age, gender, employment status, and average number of hours at work), technology use, and past experience with online discussion forums. The survey is administered online using Qualtrics software (www.qualtrics.com) and students receive a $\$ 5$ gift certificate upon completion. While the survey is not anonymous so as to link student achievement outcomes with affective outcomes, student responses are kept confidential according to IRB protocol.

The survey "The Student Opinion about Calculus Courses Survey," developed by Duke University for its NSF sponsored Project CALC: Calculus as Laboratory Course, ${ }^{16-18}$ forms the basis for the closed-ended questions in our survey and is available on the Online Evaluation Resource Library (OERL) website (oerl.sri.com). The purpose of the original survey, which closely matches the intended purpose of the survey used for this research, was to gather information about student attitudes and beliefs about their calculus class (either a Project CALC class or a regular calculus class). In its original form, the Project CALC survey consists of 40 closed-ended 4-point Likert scale questions with response categories ranging from Strongly Agree ("A") to Strongly Disagree ("D”). Somewhat Agree ("B") and Somewhat Disagree ("C") are provided as intermediate choices. Response options A through D are provided in alphabetical order, left to right.

For the purpose of the study, we tailored the original survey in several ways. We expanded the scale of each question to a 7-point scale in order to provide for sufficient variability in responses as well as a designate a true midpoint and thus allow a neutral selection. We changed the A-D response categories to numbers (1-7) and reversed the order in which the responses were provided so that a higher number represents a stronger level of agreement (1Strongly Disagree to 7- Strongly Agree with 4 - Neutral Opinion). These changes follow research-based recommendations for effective survey development provided in the literature ${ }^{19}$. Additionally, we dropped the last question that relates specifically to Project CALC since it does not fit the topic of our survey.

The original survey covered four topics or themes:

- Attitudes \& Beliefs (Student): content, engagement, impact, methods, practical value, skills

- Course Evaluation: assessment, content, methods, opportunity to practice, rigor, satisfaction

- Impact on Outcomes: confidence, knowledge, practical use, skills, student understanding

- Self-Assessment (Student): confidence, engagement, skills, understanding

We added 11 closed-ended questions to the remaining 39 from the original survey: one to address overall perceptions of learning in the course (Self Assessment) and ten to address a fifth theme: student perceptions of collaboration, community and support within the course.

Student Interviews. Students who withdraw from the course after the third week or who receive a failing grade (D or F) are asked to participate in a semi-structured interview concerning their experiences in the course. Open-ended interview questions are adapted from the Calculus in Context (CIC): Five College Consortium interview protocol available in the Online Evaluation 
Resource Library (OERL) website (www.oerl.sri.com). The purpose of this interview protocol, which closely matches the use of interviews for our project, is to gather data concerning student experiences in calculus. Students are offered a $\$ 25$ gift certificate as incentive for participating in the interview.

Participant Observation. An undergraduate research assistant (RA) gathers observational data during most class periods. The RA is introduced to the students at the beginning of the term and routinely sits in the class and takes data concerning what is occurring in the classroom, especially student-student and student-instructor interaction, questions, and general classroom behaviors of the students. Each RA splits their observational time between origination and remote sites so as to capture the breadth of student experience.

Instructor Reflection. Sometime after the midpoint of the course, the project evaluator conducts a structured interview with the calculus course instructor. The purpose of this interview is to document the current perceptions and attitudes of the instructor as he is involved in teaching the course. While it is planned that the same instructor will teach all calculus courses involved in this study to reduce significant threats to validity, we anticipate a small amount of instructional variability as part of the natural evolution of teaching. We expect the instructor's reflections will assist us in understanding how the instruction changes over time.

\section{Results and Discussion}

Based on the data gathered, the control section of Calculus I can be described as a typical distance broadcast Calculus I course. Of the 26 students initially enrolled in the course, 7 students withdrew ( 2 prior to the $3^{\text {rd }}$ week and 5 between the $3^{\text {rd }}$ and $10^{\text {th }}$ weeks of instruction) and 6 students completed the instruction but were unsuccessful (final course grade of D or F). Thus, the overall success rate for this course was 50\% (13/26), which is in line with data from prior years ${ }^{6}$.

\begin{tabular}{c|ccc|cc}
\hline Site $^{*}$ & $\begin{array}{c}\text { Student } \\
\text { Final Grade }\end{array}$ & $\begin{array}{c}\text { Quality } \\
\text { Points }\end{array}$ & Site & $\begin{array}{c}\text { Student } \\
\text { Final Grade }\end{array}$ & $\begin{array}{c}\text { Quality } \\
\text { Points }\end{array}$ \\
\hline O & F & 0 & R & C & 2 \\
O & C- & 1.67 & O & A & 4 \\
O & B- & 2.67 & R & C & 2 \\
O & B & 3.33 & O & F & 0 \\
R & B & 3.33 & O & B & 3 \\
R & A & 4 & R & B & 3 \\
R & F & 0 & O & C- & 1.67 \\
O & D & 1 & O & F & 0 \\
O & A & 4 & R & C & 2 \\
O & F & 0 & & & \\
\hline
\end{tabular}

\section{* O: Origination site R: Remote site}

Table 1.

Student Final Course Grades by Site. 
Student grades. Final course grades (based on exam and quiz scores only) by site (origination or remote) for the 19 students finishing the course are shown in Table 1. The average final grade for the course based on quality points was 1.98 ( $\mathrm{C}$ average). The average final grade for students attending at the origination site was $1.78(\mathrm{C} / \mathrm{C}$ - average $)$. For students attending at the remote sites, the average final course grade was 2.04 (C average). Of the 19 students finishing the course, 5 students attending at the origination site and 1 student attending at the remote site were unsuccessful in passing the course (grade of D or F) (See Table 1).

Student survey. The survey opened on Monday of the final $\left(15^{\text {th }}\right)$ week of course instruction. Students were sent an initial email inviting them to participate and weekly reminder emails for each of two weeks thereafter. During the fourth week after its opening, individual emails were sent to the remaining non-responders. Most respondents answered the survey within the first two weeks. Later emails, including the individually addressed emails, attracted no further response.

Description of the survey sample. The survey sample consisted of 14 (4 females and 10 males) of the 19 students completing the course. Of the 14 responding survey participants, 8 students were located at the origination site. The remaining 6 students were spread across 5 remote sites. The total number of students located at any remote site ranged between 1 and 3 .

The average reported age of the survey participants was $27.23(S D=5.07)$ and ranged from 22 to 36 . Thirteen of the 14 participants reported that they are currently employed, either part or full-time, and work an average of $37.08(S D=14.59$; Range $=15-60$ hours $)$ hours per week. Data further shows that 9 of the 14 participants (64\%) worked 35 or more hours per week and could be considered "minimally nontraditional." While we anticipate that our survey population exhibits non-traditional student characteristics to a greater extent than this, we cannot support such a claim with the data provided from this survey.

Participants were also asked to identify the types of electronic devices that they use to access course materials online (not necessarily for this course). Results indicate that most students access course material using a laptop computer $(n=12)$ or a desktop computer $(n=9)$. Students also reported using a cell phone or small mobile device $(n=9)$ and tablet $(n=4)$ to access online material. Additionally, 5 of the 14 students reported having experience using an online discussion board to receive help with course work. No student reported having prior experience specifically with the Piazza tool.

Survey results. Due to the small survey sample size $(\mathrm{n}<20)$, we have limited our analysis to descriptive statistics. Tables $1-5$ display descriptive statistics for all Likert-type scale survey items. These items have been grouped by topic into the tables for a) student attitudes and beliefs about mathematics, b) course evaluation, c) impact of course on outcomes, d) student self assessment, and e) perceptions of collaboration, community and support.

Table 2 contains the descriptive statistics for the survey items that assessed respondent attitudes and beliefs about mathematics including content, engagement, impact, methods, practical value and skills. Although the students responded that there is still more to be known about mathematics, students felt that mathematics was generally procedural in nature and one 
must know "the procedure" in order to solve a problem. Students also felt that "good" mathematics instruction centers on showing students how to solve problems. The students also responded that they generally like doing math problems (See Table 2).

\begin{tabular}{|c|c|c|}
\hline Survey Item & Mean & Std. Dev \\
\hline $\begin{array}{l}\text { Just about everything important about mathematics is } \\
\text { already known by mathematicians. }\end{array}$ & 3.07 & 1.269 \\
\hline $\begin{array}{l}\text { The best way to do well in calculus is to memorize all } \\
\text { the formulas. }\end{array}$ & 3.86 & 1.748 \\
\hline $\begin{array}{l}\text { In mathematics, you can be creative and discover things } \\
\text { by yourself. }\end{array}$ & 4.07 & 1.385 \\
\hline Some people are good at math and some just aren't. & 4.14 & 1.657 \\
\hline In mathematics, an answer is either right or it is wrong. & 4.50 & 1.506 \\
\hline $\begin{array}{l}\text { To solve math problems you have to know the exact } \\
\text { procedure for each problem, or you can't do anything. }\end{array}$ & 4.57 & 1.158 \\
\hline $\begin{array}{l}\text { Good mathematics teachers show you the exact way to } \\
\text { answer the math questions you'll be tested on. }\end{array}$ & 4.57 & 1.604 \\
\hline $\begin{array}{l}\text { Good mathematic teachers show students lots of } \\
\text { different ways to look at the same question. }\end{array}$ & 5.29 & .994 \\
\hline I enjoy doing mathematics problems. & 5.50 & 1.019 \\
\hline
\end{tabular}

Table 2.

Descriptive Statistics for Students Beliefs and Attitudes about Mathematics.

Table 3 includes the descriptive statistics for survey items related to the course evaluation including assessment, content, methods, opportunity to practice, rigor and satisfaction.

Respondents reported that while the calculus course covered a lot of material, it required more thinking than memorization and gave them problem-solving skills. Overall, students felt that the course was interesting and useful in preparing them for follow on courses (See Table 3).

\begin{tabular}{lcc}
\hline Survey Item & Mean & Std. Dev \\
\hline $\begin{array}{l}\text { Understanding of concepts was of little or no value on } \\
\text { the tests in my calculus course. }\end{array}$ & 3.14 & 1.748 \\
\hline $\begin{array}{l}\text { This calculus class was boring. } \\
\text { This calculus course should have covered more material. }\end{array}$ & 3.21 & 1.477 \\
\hline $\begin{array}{l}\text { This calculus course covered so much material too } \\
\text { quickly. }\end{array}$ & 4.86 & 1.590 \\
$\begin{array}{l}\text { On the whole, I'd say my calculus class was pretty } \\
\text { interesting. }\end{array}$ & 4.93 & 1.079 \\
\hline $\begin{array}{l}\text { In this calculus course, there was not enough time to fully } \\
\text { grasp and understand all the important concepts. }\end{array}$ & 4.93 & 1.730 \\
$\begin{array}{l}\text { This calculus course required much more thinking than } \\
\text { memorization. }\end{array}$ & 5.07 & 1.328 \\
\hline
\end{tabular}


This calculus class gave me thinking and problemsolving skills.

This calculus class prepared me to take higher level math courses.

This calculus class forced me to learn a lot of material.

This math class really required me to think about what I

was doing rather than just plugging numbers into

formulas.

Table 3.

Descriptive Statistics for the Course Evaluation Items.

Table 4 displays the descriptive statistics for survey items related to the impact of the course on desirable outcomes including confidence, knowledge, practical use, skills and understanding. In general, students felt they gained experience in applying calculus to real world problems and the course helped them to see the usefulness of math. They felt that they learned a lot and gained an understanding of the basic principles of calculus (See Table 4).

\begin{tabular}{lcc}
\hline Survey Item & Mean & Std. Dev \\
\hline $\begin{array}{l}\text { I see no practical use for what I've learned in calculus } \\
\begin{array}{l}\text { After I've forgotten all the formulas, I will still be able } \\
\text { to use the ideas presented to me in calculus. }\end{array}\end{array}$ & 2.36 & 1.646 \\
\hline $\begin{array}{l}\text { This calculus class was too theoretical, not practical } \\
\text { enough. }\end{array}$ & 4.07 & 1.351 \\
\hline $\begin{array}{l}\text { When I was in calculus, I could do some of the } \\
\text { problems, but I had no clue as to why I was doing them. }\end{array}$ & 4.43 & 1.269 \\
$\begin{array}{l}\text { In this calculus class, I had to apply calculus to real } \\
\text { world problems. }\end{array}$ & 4.71 & 1.590 \\
\hline $\begin{array}{l}\text { This calculus class helped me see how math is useful. } \\
\text { I learned a great deal in this class. }\end{array}$ & 4.79 & 1.847 \\
\hline $\begin{array}{l}\text { What I've learned in calculus will be useful to me after } \\
\text { college. }\end{array}$ & 4.86 & 1.512 \\
\hline $\begin{array}{l}\text { This calculus course helped me understand the basic } \\
\text { principles of calculus. }\end{array}$ & 5.36 & 2.093 \\
$\begin{array}{l}\text { This calculus class gave me a good understanding of } \\
\text { what calculus is all about. }\end{array}$ & 5.57 & 1.089 \\
\hline \begin{tabular}{l} 
Tabl \\
\hline
\end{tabular}
\end{tabular}

Table 4.

Descriptive Statistics for the Impact of Course on Outcomes Items.

Table 5 includes the descriptive statistics for survey items related to student self assessment, including confidence, engagement, skills and understanding. The respondents felt that while the course was challenging, it was not too difficult. They feel that they can apply what they learned and in the long run, taking calculus will be beneficial to them (see Table 5). 


\begin{tabular}{lcr}
\hline Survey Item & Mean & Std. Dev \\
\hline Most of the work in my calculus class was pretty easy. & 2.71 & 1.490 \\
\hline $\begin{array}{l}\text { I found what we learned in calculus to be dull, } \\
\text { uninteresting and a chore to learn. }\end{array}$ & 3.36 & 1.447 \\
\hline $\begin{array}{l}\text { I've applied what I've learned in calculus to my work in } \\
\text { non-mathematics courses. }\end{array}$ & 3.71 & 1.978 \\
\hline $\begin{array}{l}\text { Most of what was presented to me in calculus was too } \\
\text { difficult to grasp. }\end{array}$ & 3.86 & 1.292 \\
\hline $\begin{array}{l}\text { I feel as though I have a secure foundation in the basics of } \\
\text { calculus. }\end{array}$ & 4.43 & 1.697 \\
\hline $\begin{array}{l}\text { When I learned calculus, I think I really understood and } \\
\text { didn't just mimic techniques. }\end{array}$ & 4.64 & 1.646 \\
\hline $\begin{array}{l}\text { I feel that I can apply what I've learned in calculus to real } \\
\text { world problems. }\end{array}$ & 4.92 & 1.656 \\
\hline $\begin{array}{l}\text { In the long run, I think taking calculus will help me. } \\
\text { I'm glad I took calculus. }\end{array}$ & 5.57 & 1.453 \\
\hline
\end{tabular}

Table 5.

Descriptive Statistics for the Student Self Assessment Items.

Table 6 displays the descriptive statistics for survey items related to student perceptions of collaboration, community and support within the course. While students did not feel strongly about the benefits of student interaction (collaboration) in this course, and somewhat neutral about being a part of a learning community in the course, they did respond positively concerning perceptions of instructor provided support. Student respondents felt that there was adequate support available for the course and that the instructor was helpful and responsive in answering questions (See Table 6).

\begin{tabular}{lcc}
\hline Survey Item & Mean & Std. Dev \\
\hline $\begin{array}{l}\text { Interactions with other students in this course were } \\
\text { helpful in learning the course material. }\end{array}$ & 3.93 & 1.592 \\
$\begin{array}{l}\text { The textbook and readings were useful in learning the } \\
\text { course material. }\end{array}$ & 4.29 & 2.091 \\
\hline $\begin{array}{l}\text { In this calculus class, I felt like I was part of a learning } \\
\text { community. }\end{array}$ & 4.43 & 1.222 \\
\hline $\begin{array}{l}\text { I easily found the materials that I needed to complete } \\
\text { assignments. }\end{array}$ & 4.79 & 1.578 \\
$\begin{array}{l}\text { I knew when I could expect to hear back from the } \\
\text { instructor if I asked a question of him. }\end{array}$ & 5.29 & 1.858 \\
$\begin{array}{l}\text { Interactions with my instructor were helpful in learning } \\
\text { the course material. }\end{array}$ & 5.38 & 1.446 \\
\hline
\end{tabular}


There was plenty of support available to help me be successful in this course.

$5.43 \quad .938$

The purpose of course activities (e.g. readings, assignments, discussions, quizzes, etc.) were clearly

explained.

I felt like I had plenty of opportunities to ask questions and receive answers.

$5.50 \quad 1.401$

I knew what is expected of me in terms of participation in the course.

\section{Table 6.}

Descriptive Statistics for Collaboration, Community and Support Items.

In summary, the descriptive statistical data suggests that the 14 students who completed this survey were generally positive concerning mathematics in general and the course, its impact, and their own progress in particular. The data also indicates that instructor based support was considered most helpful to learning and that students felt well supported in this course. Peer-topeer collaboration and interactions were perceived to be less helpful to learning in this course.

Student interviews. Interviews were conducted after the $10^{\text {th }}$ week of instruction with students withdrawing from the course and at the end of the course (after course grades were posted) with students receiving final course grades of D or F. The tailored interview questions posed to the interviewees were:

- What is your major?

- Have you taken calculus before? If so when and where?

- Where were you based?

- One a scale of 1-5 (5 being highest), what is your interest in mathematics?

- What were your expectations for Math 1210 Calculus I?

- What aspects of the course facilitated your learning of the subject material (e.g. lectures, in-class problem solving, textbook, homework, group work, etc.)?

- How would you describe the workload in Math 1210 (heavy, about right, light)?

- What took the most time and effort in Math 1210?

- Did the course reduce or increase your anxiety about math?

- What was responsible for these changes?

- What were your reasons for opting out of Math 1210 in Fall 2013?

Interviews were audio recorded and transcribed. Subsequently, a joint analysis (PI, co-PI program evaluator and education research consultant) was performed on the interview responses to identify common themes emerging from the experiences of the students.

Students who withdrew from the course. All 5 students who dropped the course after the 3rd week were contacted via email and phone by the project evaluator to request an interview concerning their experiences in the course. Although several requests were made to each, only 2 students agreed to participate. Both of these students elected to respond to the interview questions via email, declining synchronous face-to-face or video interviews. 
Description of the interviewees. Both interview participants had been located at remote sites during the course and had taken calculus previously. One student, "Student A", was retaking Calculus I in an attempt to achieve a higher grade. Student A, whose stated major goal was to learn how to use calculus in real life applications, expressed a moderate (3/5) interest level in mathematics. Student B had previously taken a calculus course but was taking Calculus I with the expectation to "adequately learn calculus". Student B expressed a high interest level $(5 / 5)$ in mathematics. Both students dropped the course without contacting the instructor.

Emergent theme. A common theme that emerged from the email responses of students who withdrew was a perceived lack of instructional support and incompatibility with the instruction as presented. This incompatibility was combined with a feeling of being unable to "teach themselves." In describing the classroom experience, Student A commented that "...nothing was learned in class from the instructor... [the instructor] offered nothing but confusion and anxiety..." and that self-study took the most time and effort in the course. Student A went on to say that "...most classes were spent with the volume off and ... students teaching each other...." Student A was located at a remote site that served more than one student. When dissatisfied with the instruction, Student A opted for peer instruction and collaboration. Student A later withdrew from the course.

Unlike Student A, Student B was solely located at a remote site. Similar to Student A, Student B commented that "trying to teach myself" took the most time and effort in the course. Student B further stated:

The whole class was lecture...I had a hard time following what [the instructor] was demonstrating... It was too stressful. I didn't feel I had enough time to reteach myself the material. I wasn't prepared for the way it was taught....

Upon failing the first exam, Student B, self-described at this point as "overwhelmed" and "too stressed out", opted to withdraw from the course with the resolve to retake it "...when I don't have so much going on so I can study twice as hard." Thus, Student B's physical isolation seemed to limit an ability to see other techniques or strategies, apart from self-instruction, to learn the course material.

Students with course grades of $\boldsymbol{D}$ or $\boldsymbol{F}$. Of the 19 students finishing the course, 6 (32\%) received final grades of D or F. The PI contacted all 6 students via email to request an interview concerning their experiences in the course. Although several requests were made, only 3 ( 1 female, 2 male) students responded. All 3 agreed to a face-to-face interview conducted by the PI.

Description of the interviewees. Two of the interviewees, Student C and D, attended the course at the origination site. One student, Student E, attended at a remote site. All three had taken distance courses (synchronous or asynchronous) prior to enrolling in this course. All three were new to calculus and had never taken a calculus class before. Two students, Students C and E, specifically mentioned being good at math in high school although both had experienced gaps in their education between high school and college. 
From the interviews we quickly learned of the complexity and fullness of the lives of these students. All of the students were parents; one student was a single parent. All of the students worked full time to support their families. All of the students were attending college some time after graduating high school. Thus all of these students could be characterized as moderately nontraditional based on Horn's continuum ${ }^{14}$. It is very likely that, with more information, some if not all of these students could be characterized as highly nontraditional.

Emergent themes. Similar to the students who withdrew from the course, Students $\mathrm{C}$ and $\mathrm{D}$ felt that their learning styles were incompatible with the way in which the material was presented in the classroom. Student D explained this idea saying,

...The instructor using examples word for word out of the book it kinda, that made it hard for me to, to be able to grasp a lot of the concepts because they were a little bit broader than what my understanding was and I wasn't able to connect the pieces.

Interestingly, Student $\mathrm{C}$ and $\mathrm{D}$ reacted quite differently to their perceived incompatibility with the method of instruction. Student $C$ stopped coming to class and instead watched the recorded lectures, skipping past the formal presentation to places in the video where the instructor more freely explained the problems. Student D, however, never missed a class. Student E, on the other hand, explained that he liked the instruction saying, 'I do like the way that he [the instructor] did it [wrote out his lecture notes] because that's the way I grew up knowing." Student E did not adopt any other learning support activities other than coming to class, reading the textbook and attempting the homework.

What is most interesting about these responses is not that there were students who did not mesh with the instructor's style - this is inevitable — but rather that there were such disparate and personalized ways in which these students went about getting support outside of class. In addition to watching the recorded course lectures, Student $C$ regularly watched Khan Academy videos, recommended by Student's C's teenage daughter. Student D continued attending class but also sought help from a neighbor who used to teach calculus. None of the three students attended the bi-weekly office hours or felt that doing so was even an option for them based on their personal work schedules and familial responsibilities. Moreover, none of the three students emailed the instructor when they had a question or to tell him they needed help. Student $\mathrm{C}$ did not feel comfortable being able to express a calculus question well enough through email to get a worthwhile response. Student C stated that "I wouldn't even have known how to ask the question, it would have been like I have no idea what I'm doing." Student D had personal computer trouble during a significant portion of the course and was not able to email. Student E confessed to not emailing much but instead suggested that online video conferencing would be a better alternative. It seems that these distance students did not adapt to available support mechanisms and sought alternative, highly personalized approaches to gain the type of help they desired.

A second theme that emerged was the students' perceptions of the benefits of peer-topeer collaboration. All three students suggested that more group work and peer interaction would have helped their learning in this course. Student $\mathrm{C}$ remarked that, during the few times that the 
instructor had the students work in groups, it was "... not just helpful but like comforting to know that the other people were as lost as I was on some things..." Student D, who regularly worked on calculus with three other friends from another course, commented that, "... talking with a lot of the students helped me out with understanding some of it." Student E, who was located at a remote site, felt that required or mandatory peer interaction in class would have helped him in gaining a better understanding of the material:

I think I struggled with a lot of calculus concepts because I didn't ask questions and I'm kinda like an independent person-I kind of can figure it out myself. And then I don't end up figuring it out quite the way I need to. And I think having like mandatory groups...could help, definitely.

This last excerpt is important because it points to another perception that all three students voiced: the mental shift required when one begins study of calculus. Student E, echoing the comments of the others, called calculus "... a different animal." That previous success in mathematics does not insure success in calculus is not apparent to many first time calculus takers. Students who have been successful at pre-calculus mathematics may be more at risk for struggles in calculus because they have little experience with getting additional help. As Student E discussed, many successful high school students are used to figuring it out for themselves and may come understand too late that they cannot learn calculus alone.

Located at a small remote site, Student E admitted to not talking to calculus classmates much and thought doing so would have been easier if more students had been located at the remote site. Therefore, it seems that there is a threat for distance learning environments to exacerbate these individualistic tendencies by enabling students to only passively attend class instead of actively participate in building knowledge. Perhaps it is true that not all calculus-ready students may have the developed the necessary skills needed to persist and succeed in college calculus.

Classroom observation. Observation notes were initially handwritten and later transcribed into electronic format by RA. The notes were provided to the research team (PI, coPI, evaluator, education research consultant and RA) and jointly analyzed at two sequential research meetings to discover themes present in the data. Several themes were gathered from the observational data.

The context of instruction. One of the primary purposes of observational data is to provide a separate account, from the viewpoint of an undergraduate student who is not enrolled in the course, of the course instruction and interaction. As researchers and colleagues, we know of the instructor's achievements, experience, competencies, and personality. But who is the instructor in the eyes of undergraduates? How does the instruction appear to them?

From observation notes and discussion, we begin to develop a picture of the instruction in the course. Pedagogy was primarily lecture and demonstration, and content centered. Each class period tended to unfold similarly: announcements, an opportunity for student questions, a quiz (if scheduled for the day), lecture on new material combined with demonstrations of problem 
solving. There was also, usually, a five-minute warning prior to the end of the period. Students quickly grew accustomed to the schedule and regularity of the instruction.

Although taught via distance delivery, the instruction remained relatively unencumbered with technology. The instructor did not own a cell phone. The instructor's online presence may be described as sufficient, consisting of a course website and an email address. Students were supported via questions taken in class, physical office hours, phone and email. Recently, the instructor had begun to capture his lectures on video recordings and post them for student viewing and the students seem to use them.

Interaction. Observational data suggests that there was a greater level of interaction occurring between the instructor and students at the origination site than between the instructor and students at the remote sites. The first question of the day was almost always posed by someone at the origination site. Students at remote sites rarely answered questions posed by the instructor while students at the origination site dominated content related conversations with the instructor. The atmosphere at the origination site was different too- "apprehensive", "alert" and "tense" - while that of the remote site was "calm" and "quiet." The instructor is quite funny and often used humor. Unlike those at the origination site, students at the remote sites seldom laughed. Students at the origination site seemed to find the instructor approachable and often asked questions "off camera" during breaks or at the end of class.

Partnering. Over time, there were several examples of co-situated students beginning to form partners or pairs. Pairs tended to form among those sharing a common experience outside of the course - another class, a common activity, etc. Student partners sat together, shared social interaction, and collaborated on course material during class. Not all students paired up however. Many students remained solitary. Groups larger than two did not seem to form.

Instructor reflection. The program evaluator conducted the instructor reflection interview during the $9^{\text {th }}$ week of instruction. The interview was audio recorded and later transcribed. A joint analysis (PI and program evaluator) was performed on the interview responses to identify common themes emerging from the mid course reflections of the instructor.

At the time of the interview the instructor was aware that several students had recently withdrawn from the course. The students had not contacted him prior to doing so. The instructor remarked that he does not feel this is unusual and assumes the withdrawals are related to scores on the first exam. He is very aware of the non-traditional student body he serves and understands that they face many issues in completing their education.

The instructor remarked that the distribution of exam scores and amount of attrition seemed on par with his previous experience teaching the course. The instructor commented that this class is one of the largest Calculus I classes he has had (he has many students at the origination site with him, in past years that has not been the case) and contributes much of the growth to the distance-delivered engineering program.

Interaction. Overall the instructor is excited by the interest and enthusiasm of the students in the course and the classroom interaction they are providing. He is, however, 
concerned with the way that the origination site dominates the classroom conversation. Not only does he notice the disparity, he expressed desire to change the situation: "I interact much better with the students that are in the classroom with me because I can see their faces and anyway it is much easier... I should make an effort to overcome that." Additionally, the instructor expressed some frustration with the current state of the IVC technology that does not allow the classroom display to be large enough to see individual students during the class. He feels this "glitch" in the technology affects his ability to connect with students at the remote sites.

Support vs. instruction. The instructor was generally pleased by the student questions being asked in class, during office hours, via emails and phone because, as he says, "I take it as a sign they are engaging with the homework." He realized, however, that the amount of questions asked in class can be a double edged sword because "...you know, it does take time to address all of those questions." He explained that the number of questions is causing him to fall behind his schedule and that maintaining the schedule is important because Calculus I is a pre-requisite to Calculus II. As an instructor, he explained that he does not "control" what is on the syllabus, yet he is responsible to insure that all of the required material is covered. The instructor seemed to take this responsibility deeply to heart. On the other hand, he expressed that he also feels responsibility to adequately address questions if students have them and are interested enough to bring them up in class. Falling behind seems to be a relatively new problem for him. There is a sense that the instructor is conflicted concerning this issue.

\section{Conclusions}

In holistically examining the results of the quantitative and qualitative data gathered in the Calculus I control section, we conclude that our methodological choice of a concurrent mixed methods approach is justified. Our rationale of "completeness," that the use of both quantitative and qualitative methods can be used to produce a more "comprehensive account of the area of inquiry," 15 appears to be exactly what is happening during the practice of our study.

For example, in using only quantitative survey data, we may conclude that there is adequate learning support for the students and there are no issues to be considered. The quantitative achievement data may cast a shadow on this conclusion but, without additional insights, it is difficult to understand why the students on average performed at a mediocre level when they were as generally well supported, content with the learning environment, and interested in the subject matter as the survey data seems to indicate.

On the other hand, using only the qualitative interview data from the non-persisting or unsuccessful students, we may surmise that more instructor-based support or perhaps significant pedagogical change is needed. There may be a tendency to see only the problems and not notice the things going well in the course. We may not see that the instructor is afforded a great amount of trust by his students or that the students feel is he approachable and overall a good teacher, especially when he speaks less formally and more from the cuff. It seems as if the instructor is in an excellent position to influence his students approach to learning in a productive way. This understanding may have been lost without the quantitative survey data.

In essence, it is only as we look across the breadth of the data that we see a more complex picture wherein instructor and students appear to repeatedly fall back on traditional support 
mechanisms (instructor answering question in class, email, physical office hours) despite being situated in a distance delivered course. Although many signs point to the fact that these support methods are not adequate for the learning environment or for the learners served by the course, they continue to predominate. Despite many warning signs (very low attendance at office hours, low email rates, high volumes of questions from previous material during class, low exam scores), there was minimal communication between the instructor and students concerning what is needed and what can be done better or changed. Instead, struggling students pursued individualized options for self-help: self-instruction, Khan Academy, a neighbor who used to teach calculus. Students remained content with the course and basically pleased with the instruction seemingly because the instructor, as is traditional, spent significant portions of class time answering questions on homework.

Another important finding to consider is the agreement among the unsuccessful students that were interviewed that planned, consistent and even required peer-to-peer interaction would have helped them achieve better in this course. The call for peer-to-peer interaction as a part of good teaching and learning practice is not new. In fact, developing "reciprocity and cooperation among students" is listed as one of Chickering and Gamson's "Seven Principles for Good Practice in Education. ${ }^{, 20}$ Social constructivism suggests that both the depth of and motivation for learning depends on the ability to socially construct knowledge amidst culturally accepted and formalized concepts ${ }^{21}$. Developing a strategy for effective peer collaboration is not only important to promote deep learning, but holds implications for reducing instructor workload as well. Today's instructors teach demanding course loads. Teaching via distance adds to the burden. Interventions and tools capable of providing consistent student and instructor interaction hold promise for improving instructor and student outcomes in this type of learning environment.

Finally, our analysis of the data collected from the Calculus I control section suggests that there is a need to further tailor our survey questions in order to collect more detailed information concerning student impressions of learning communities and the social aspects of learning in the course, the degree to which students found working with other students helpful, the activities that student thought were the most helpful for learning, and student demographics. Additional student demographic questions are needed in order to better describe the degree of nontraditionality of the students in the course. The data gathered from the revised survey will allow us to more fully link the quantitative survey data with the qualitative interview data.

In combining the individual pictures of the Calculus I course that each data set provides, we are able to construct a richer, multi-faceted view consistent with the breadth of student experience. In this way, the combined data analysis provides a more useful baseline with which to compare the experience of students in the Calculus I treatment section. In turn, a strong comparison should provide more insightful and compelling input for the online forum usage model that is a deliverable of the overall project.

\section{Acknowledgements}

This paper is based on research funded by the National Science Foundation under Award number DUE 1245194. Any opinions, findings, conclusions or recommendations expressed in 
this material are those of the author(s) and do not necessarily reflect the views of the National Science Foundation.

This research is conducted under our university IRB protocol 4532.

\section{References}

[1] Freeman, R.B. (2005). Does globalization of the scientific/engineering workforce threaten U. S. economic leadership? National Bureau of Economic Research (NBER). Working Paper \#11457.

[2] Sevo, R. (2009). The talent crisis in science and engineering. In B. Bogue and E. Cady (Eds.), Apply Research to Practice. ARP Resources.

[3] Gardner, J. F., Pyke, P.A., Belcheir, M. J., and Shrader, C. B. (2007). Testing our assumptions: Mathematics preparation and its role in engineering student success. Proceedings of the 114th ASEE Annual Conference and Exposition, Honolulu, HI.

[4] Budny, D., LeBold, W., and Bjedov, G. (1998) Assessment of the impact of freshman engineering courses. Journal of Engineering Education, 87, 405-441.

[5] Koch D. and Herin G. (2006). Intervention strategy for improving success rates in calculus. Proceedings of the 113th ASEE Annual Conference and Exposition, Chicago, IL.

[6] Minichiello, A. and Hailey, C. (2013). Engaging students for success in calculus with online learning forums. Proceedings of the 43rd ASEE/IEEE Frontiers in Education Conference, Oklahoma City, OK.

[7] Tashakkori, A. and Teddlie, C. (2003). Handbook of Mixed Methods in Social and Behavioral Research. Sage, Thousand Oaks, CA.

[8] Kozulin, A. (1990). Vygotsky's psychology: A biography of ideas. Harvard University Press, Cambridge, MA.

[9] Daniels, H. (Ed.). (2005). An introduction to Vygotsky. (2nd ed.). Routledge, New Work, NY.

[10] Rieber, R. W. and Carton, A. S. (Eds.). (1987). The collected works of L. S. Vygotsky (Vol. 1). Plenum Press, New York, NY.

[11] Bransford, J. D., Brown, A. L. and Cocking, R. R. (1999). Learning and transfer. How people learn: Brain, mind, experience, and school (pp. 39-66). National Academy Press, Washington, D.C.

[12] Lerman, S. (1996). Intersubjectivity in Mathematics Learning: A Challenge to the Radical Constructivist Paradigm? Journal for Research in Mathematics Education, 27 (2), 133-150.

[13] U.S. Department of Education Statistics, NCES. (2002). Nontraditional Undergraduates (NCES 2002-012). U.S. Government Printing Office, Washington, DC.

[14] Horn, L. (1996). U.S. Department of Education, U.S. Government Printing Office, Washington, DC.

[15] Bryman, A. (2006). Integrating quantitative and qualitative research: how is it done? Qualitiative Research, 6(1), 97-113. 
[16] Bookman J. and Friedman, C. (1993). Student attitudes and calculus reform. School Science and Mathematics, 98(3), 117-122.

[17] Bookman J. and Friedman, C. (1994). A comparison of the problem solving performance of students in lab based and traditional calculus. Issues in Mathematics Education, 4, 101-116.

[18] Bookman, J. and Blake, L. (1996). Seven years of Project CALC at Duke University approaching steady state? Problems, Resources, and Issues in Mathematics Undergraduate Studies (PRIMUS), VI(3), 221-234.

[19] Dillman, D. , Smith J. D., and Melani Christain, L. (2009). Internet, Mail and Mixed-Mode Surveys: The Tailored Design Method. John Wiley \& Sons, Hoboken, NJ.

[20] Chickering, A. W. and Gamson Z. F. (1987) Seven Principles for Good Practice in Education. American Association of Higher Education Bulletin, 39(7), 3-7.

[21] Fosnot, C. T. (1996). Constructivism: A psychological theory of learning. In C. T. Fosnot (Ed.), Constructivism: Theory, Perspectives and Practice. Teachers College Press. 